\title{
A saúde entre a iniqüidade e a justiça: contribuições da igualdade complexa de Amartya Sen
}

\author{
Health between iniquity and justice: \\ contributions of complex equality \\ in Amartya Sen
}

Rodrigo Siqueira-Batista 1

Fermin Roland Schramm 2

\footnotetext{
1 Faculdade de Medicina de Teresópolis, Fundação Educacional Serra dos Órgãos (FESO), Núcleo de Estudos em Filosofia e Saúde (NEFISA/FESO), Departamento de Ciências Sociais (DCS) da Escola Nacional de Saúde Pública, Fundação Oswaldo Cruz (ENSP/Fiocruz).

Av. Alberto Torres 111, Alto, 25964-000, Teresópolis RJ. anaximandro@hotmail.com

2 Departamento de Ciências Sociais, Escola Nacional de Saúde Pública, Fundação Oswaldo Cruz (DCS/ENSP/Fiocruz).
}

\begin{abstract}
Justice, as a dimension of the medical practice, gives rise to problems that have yet to be solved. The whole discussion on equity can be traced back to Greek antiquity, being however extremely present in its applications to health from a perspective seeking a coalition between equality and difference. Updating the impact of the inequalities in the binomial term health-disease, enlightened by the contributions of the Indian economist Amartya Sen will be the path followed by this essay.

Key words Inequality, Poverty, Equity, Justice, Health, Sen
\end{abstract}

Resumo A justiça, como dimensão das práticas em saúde, corresponde a um problema que segue aguardando por melhores equacionamentos. Todo o debate sobre a eqüidade pode ser recuperado desde a Antigüidade grega, colocando-se, entretanto, como extremamente atual em suas aplicações à saúde, desde uma perspectiva em que se procure a coalizão entre igualdade e diferença. Atualizar o impacto das desigualdades no binômio saúde-doença, matizando este horizonte à luz das contribuições do economista indiano Amartya Sen, é o caminho a ser percorrido no presente ensaio.

Palavras-chave Desigualdade, Pobreza, Eqüidade, Justiça, Saúde, Sen 


\section{Introdução}

Zé Brasil era pobre coitado. Nasceu e sempre viveu em casebres de sapé e barro, desses de chão batido e sem mobília nenhuma - só a mesa encardida, o banco duro, o mocho de três pernas, uns caixões, umas cuias... Nem cama tinha. Zé Brasil sempre dormiu em esteiras de tábua. Que mais na casa? A espingardinha, o pote d'água, o caco de sela, o rabo de tatu, a arca, o facão, um santinho na parede. Livros, só folhinhas - para ver as luas e se vai chover ou não, e aquele livrinho do Fontoura com histórias do Jeca Tatu. - Coitado deste Jeca! - Dizia Zé Brasil olhando para aquelas figuras. -Tal qual eu. Tudo que ele tinha, eu também tenho. A mesma opilação, a mesma maleita, a mesma miséria e até o mesmo cachorrinho (Monteiro Lobato).

O debate sobre a justiça, no âmbito da saúde pública, vem experimentando um decisivo aprofundamento nas duas últimas décadas, mormente nas sociedades latino-americanas (Cordeiro, 2001; Viana et al.., 2003). Já no final dos anos 70, em meio a severa crise econômica que assolava diversas nações do Hemisfério Sul, colocavam-se questões relativas à organização de um sistema de saúde capaz de atender as demandas da população - nos diversos níveis de atenção -, o que pressupunha uma otimização dos gastos em pleno horizonte de escassez de subsídios, concordes com uma adequada e responsável política de alocação de recursos (Kottow, 2000; Vergara, 2000).

No Brasil, o sistema de assistência à saúde vigente na ocasião era marcadamente excludente, deixando de fora os menos favorecidos, habitualmente os mais ameaçados por diferentes agravos (Viana et al., 2003). As discussões transcorreram de forma concomitante - mas não necessariamente combinada - ao processo de abertura política, que se iniciou após vários anos de ditadura militar (Alencar et al., 1988; Siqueira-Batista, 1996), durante os quais fora vivenciada uma genuína “suspensão" dos direitos civis e políticos, ainda que com algum ganho no espaço dos direitos sociais (Magalhães, 1997). Nesse período de redemocratização houve marcante incremento nos debates, garantindo-se a ampliação da participação social e do exercício da cidadania. A culminância deste processo foi a promulgação da Constituição Federal em 5 de outubro de 1988, cuja dimensão progressista, no que se refere à saúde, tor- na-se manifesta no artigo 196, o qual dispõe sobre o papel do Estado, nos seguintes termos: A saúde é um direito de todos e um dever do Estado, garantido mediante políticas sociais e econômicas que visem à redução do risco de doença $e$ de outros agravos e ao acesso universal e igualitário às ações e serviços para sua promoção, proteção e recuperação (Brasil, 2000).

O texto manifesta claramente princípios de universalidade e de igualdade no acesso à saúde, tendo como pressuposto, inequívoco, a idéia de justiça social capaz de garantir tal direito consubstancial à sociedade. Estes fios condutores - associados à integralidade da assistência e à descentralização da gestão - representam, em última análise, as normas fundamentais que regem o Sistema Único de Saúde (SUS), um novo modelo, ou paradigma, que tem, como metas, maior eqüidade, viabilidade fiscal e financeira, além do aprimoramento da eficiência, da qualidade e da satisfação dos usuários (Cordeiro, 2001).

Em 1990, inicia-se a promulgação das normas operacionais e leis orgânicas para tornar viável o modelo SUS. Entretanto, a ausência de um pacto político mais amplo para concretizar este seu desenho primevo (não atuaram nesta fase as organizações dos profissionais de saúde e o empresariado da área médica, apenas para citar dois exemplos) culminou em resistências de diferentes naturezas, as quais tornaram extremamente complexa a implementação do projeto (Labra, 2001; van Stralen, 1996).

Apesar dos avanços obtidos, em termos éticos e políticos, com o advento do SUS, aspectos como o papel do Estado - entendido como autêntico promotor de saúde ou como mero regulador de conflitos -, a necessidade de combinar os princípios maximalistas da universalidade, igualdade e integralidade com políticas sanitárias pragmáticas de descentralização, focalização e a otimização dos gastos públicos demandaram uma permanente atualização crítica, no âmago do trabalho reflexivo sobre a real eficácia e efetividade das políticas públicas. Isso fez com que surgissem, ao longo da implementação do paradigma SUS, uma série de problemas ética e politicamente relevantes, tais como:

- a tensão resultante da diretriz de proporcionar o acesso universal à saúde - isto é, a todas as pessoas - em um contexto de demandas cada vez maiores, por um lado, e de recursos cada vez mais limitados, por outro;

- o problema de assegurar o tratamento igualitário de indivíduos com inserções sociais tão 
díspares, muitos dos quais, na verdade, efetivamente não inseridos, como no caso dos milhões de excluídos no País; e

- o desafio de compor os dois elementos anteriores em um ideal mais amplo de justiça qual seria ele? - algo imprescindível, sobretudo para uma sociedade tão desigual quanto a brasileira, indicada pela feliz expressão "os muitos brasis” (Minayo \& Minayo, 1999).

Acolhendo estas dimensões como cruciais, procurar-se-á desenvolver uma reflexão com base nos seguintes eixos: 1) a desigualdade social e seu impacto sobre a saúde da população; 2) o alcance das concepções de igualdade e justiça no debate atual sobre a saúde; e 3) a aplicação de um referencial de igualdade complexa à questão da justiça sanitária, com base nas elaborações teóricas do economista Amartya Sen.

\section{O que se tem...}

\section{Pobreza, desigualdade e exclusão social: horizontes na saúde}

Os conceitos pobreza, desigualdade e exclusão são, muito freqüentemente, usados em associação para delimitar fenômenos que costumam estar intimamente relacionados. Mas, de acordo com o método da complexidade, é preciso saber reunir sem confundir e distinguir sem separar. Não pretendendo ingressar no "espinhoso" debate sobre cada um destes termos - o que motivaria a preparação de vários artigos -, estabelecer-se-á, a seguir, linhas gerais para que seja melhor compreendido o "lugar" de onde se está falando no presente ensaio.

A pobreza, classicamente delimitada em termos de renda, é hoje vista de forma muito mais ampla. Relaciona-se à privação dos itens mais necessários à existência digna, tais como liberdade, bem-estar, saúde, educação, direitos, emprego, meios para participar do mercado de consumo, e tantos outros quanto se possa pensar (Veras, 1999), tal qual o delimitado por Rocha (2003): Pobreza é um fenômeno complexo, podendo ser definido de forma genérica como a situação na qual as necessidades não são atendidas de forma adequada (Rocha, 2003).

Por desigualdade entende-se a "distância" social entre os mais ricos e os mais pobres em uma dada situação. Neste âmbito, o caso do Brasil é modelar: em 1999, o 1\% mais abastado se apropriou de $13 \%$ do rendimento total daquele ano, proporção bastante próxima do que foi apossado pelos 50\% mais pobres (Rocha, 2003). Tal ca- racterização da desigualdade encontra-se limpidamente manifesta no excerto de Telles (1994), ao comentar a situação nacional:

O que faz a nossa diferença está no fato de sermos uma sociedade atravessada por hierarquias de todos os tipos, que se construiu ao revés do imaginário igualitário fundador dos "tempos modernos" e nem mesmo chegou a garantir o princípio básico de equivalência jurídica que a noção de igualdade supõe. Uma sociedade na qual distâncias sociais são tão grandes que parece implausível uma medida comum que permita que a gestão da justiça coloque-se como problema e critério de julgamento nas relações sociais -o fosso social é tão imenso que parece obstruir a possibilidade mesma de uma linguagem comum e, portanto, do convívio social, interlocução e debate comum em torno de questões pertinentes. Isso é propriamente o apartheid social (Telles, 1994).

Tal percepção de apartheid se aproxima, outrossim, da idéia de exclusão. Esta pode ser compreendida no "rastro" do incremento da pobreza como geratriz da desigualdade e da perpetuação das mais diversas formas de segregação social, culminando nos reconhecidos filões de indivíduos não inseridos (Nascimento, 1994; Veras, 1999). A exclusão é considerada por Paugam (1999) como um conceito prospectivo (concept-horizon), que albergaria quesitos como acúmulo de desvantagens, afrouxamento dos vínculos sociais e perda do lugar ocupado em uma sociedade.

A partir dessas "ferramentas" preliminares - representadas pelos conceitos de pobreza, desigualdade e exclusão - pode-se analisar o fato de o Brasil encontrar-se entre os países em que a renda per capita seria suficiente para garantir o mínimo essencial a todos os seus habitantes no ano de 2000, seu valor foi de $\mathrm{R} \$ 3.500,00-$, mas que, pela terrível iniqüidade na distribuição de renda, mantém-se como uma nação em que subsistem a privação e terríveis distâncias sociais (Barros et al., 2000; Rocha, 2003).

Esta organização espúria traz graves reflexos nos aspectos relacionados à condição sanitária da população. De fato, grande número de investigações tem demonstrado, de maneira bastante consistente, as relações entre agravos à saúde e o nível socioeconômico (Castellanos, 1997; Silva et al., 1999), sendo os países mais pobres aqueles que tendem a apresentar um pior desempenho sanitário em relação aos mais abastados; ademais, em um mesmo povo, díspares condições mórbidas grassam prioritaria- 
mente entre os menos favorecidos (Fleury, 1995; Silva et al., 1999). Em suma, os mais pobres tendem a ter uma menor expectativa de vida, a permanecer mais dias de suas vidas vitimados por moléstias e sofrer limitações relevantes em suas atividades (Wagstaff, 2001).

A distribuição diferenciada da desnutrição, as relações entre a mortalidade (p. ex., infantil) e as classes sociais, a associação dos indicadores de saúde às variáveis socioeconômicas (p. ex., expectativa de vida), a relação entre câncer de colo uterino e o estrato social são apenas alguns dos exemplos de pesquisas que estabelecem, muito claramente, o quanto a iniqüidade social é capaz de se impor decisivamente no binômio saúde-doença (Engel et al., 2001; Paim \& Costa, 1993; Victora et al., 1989).

Desigualdade, pobreza e enfermidade constituem, assim, um típico movimento de retroalimentação, tal qual o denunciado por Wagstaff: A associação entre a pobreza e a doença reflete uma relação de causalidade bidirecional. A enfermidade ou a fecundidade excessivamente alta podem ter um considerável efeito nos rendimentos familiares e marcar, inclusive, a diferença de se estar acima ou abaixo da linha de pobre$z a$. Ademais, a doença se associa freqüentemente a consideráveis custos de atenção sanitária. Mas a pobreza e os baixos rendimentos também são causa de moléstia. Os países pobres e as pessoas pobres sofrem múltiplas privações que se expressam em altos niveis de enfermidades. Deste modo, as pessoas pobres se vêem enredadas em um círculo vicioso: a pobreza engendra doença e esta mantém a pobreza (Wagstaff, 2002).

Como pode ser explicado este círculo vicioso? Em verdade, aqui entram em cena múltiplos fatores, a saber:

1) nível educacional - é menor o tempo de escolaridade e maiores os índices de analfabetismo entre os desfavorecidos -, uma vez que uma formação deficitária contribui para o desconhecimento dos mecanismos de adoecimento e das formas de prevenção e tratamento (por exemplo, o uso de reidratação oral é menor nas crianças pobres, ainda que a diarréia seja mais freqüente neste grupo) (Wagstaff, 2002);

2) violência - ainda que sua relação com a pobreza e a desigualdade não seja linear, a associação vem sendo demonstrada em diversos trabalhos -, tornando os residentes nas regiões de periferia e favelas mais suscetíveis a lesões por armas e morte por causas externas (Macedo et al., 2001; Minayo, 1998; 2003; Njaine \& Minayo, 2002);
3) saneamento básico - habitualmente precário nas regiões mais miseráveis - facilitando o adoecimento pelo grande contingente de enfermidades veiculadas por recursos hídricos, como as diarréias infecciosas e a leptospirose, entre outras (Santos et al., 2001; Girotto et al., 2003); 4) insuficiência (ou falência) do sistema de saúde - distância, condições de transporte, precariedade de instalações, falta de insumos, pior treinamento e desmotivação dos profissionais, entre outros -, criando toda uma série de dificuldades de acesso aos diferentes níveis de atenção (Lavy et al., 1996).

Poder-se-iam, evidentemente, arrolar outros elementos, mas estes parecem suficientes para delinear o panorama de inter-relações entre pobreza, desigualdade e exclusão social, com sério impacto sobre as condições de saúde desse segmento populacional, visto que as circunstâncias geradoras de moléstias acabam por se perpetuar, uma vez que os enfermos têm maior absenteísmo laboral - muitas vezes no mercado informal, sem qualquer garantia trabalhista (Brito Quintana, 2000) -, permanecendo períodos variáveis sem os rendimentos capazes de garantir a subsistência familiar, retroalimentando, portanto, a precariedade das condições de saúde.

$\mathrm{O}$ que pesa, em relação às sociedades latino-americanas, são os séculos de exploração e opressão, como belamente expresso por Eduardo Galeano em As veias abertas da América Latina (Galeano, 1994). Mantendo o mesmo tom, Aluísio Azevedo, no romance O cortiço - escrito no final do século 19 (1890) - traça um retrato da miséria e da desigualdade na cidade do Rio de Janeiro. Nos trechos abaixo, há referências à precária condição de higiene do cortiço de João Romão e a uma das moléstias que assolavam o município:

- Quero isto limpo! bramava furioso. Está pior que um chiqueiro de porcos! Apre! Tomara que a febre amarela os lamba a todos! [...]

Delporto e Pompeo foram varridos pela febre amarela e três outros italianos estiveram em risco de vida (Azevedo, 1997).

Não fosse a menção à febre amarela, doença erradicada no Estado (poder-se-ia, no entanto, substituí-la tranqüilamente pela dengue) e o comentário em relação aos italianos (imigrantes à época, hoje, em geral, turistas), a descrição poderia, perfeitamente, referir-se a uma das favelas cariocas nestes primórdios de século 21. Tal situação não se manteve estável ao longo destes mais de 100 anos: outrossim, so- 
freu nítido agravamento (nunca a desigualdade e a concentração de renda foram tão expressivas no País). Tentativas supostamente miraculosas, mormente as políticas econômicas neoliberais, de fato aguçam as distâncias entre ricos e pobres. Por exemplo, a tão propalada globalização, panacéia muitas vezes anunciada como resolução para as disparidades internacionais e sociais, mais parece uma fábula - em relação à distribuição de renda -, tal qual um mito do desenvolvimento econômico (Furtado, 1974).

Como romper esta lógica sanitária nefasta, uma mostra legítima da rotunda contradição do sistema capitalista? Antes de mais nada, fazse necessário reconhecer que a desigualdade no âmbito da saúde é um sintoma da iniqüidade social - em um sentido mais amplo -, possuindo, outrossim, díspares mecanismos de "autoorganização” nos diferentes países. Esta constatação têm implicações decisivas no "campo de atuação" para a redução das desigualdades sociais em saúde, podendo, de outro modo, tornar-se um poderoso estímulo para a formulação de diferentes estratégias visando à redução das injustiças.

Mas... seria realmente possível a justiça como igualdade?

\section{O que se almeja... \\ Igualdade, eqüidade e justiça: alguns recortes}

A despeito de sua grande preeminência nas sociedades laicas e plurais contemporâneas, a reflexão sobre a igualdade e a justiça como eqüidade são manifestações muito arcaicas do Espírito humano, remontando ao mundo helênico. A noção de igualdade entre os homens nasce no mesmo processo em que se constitui a atividade política no Ocidente. A pólis, cerne da organização política grega nos períodos arcaico e clássico, se constitui sobre a igualdade ( $\sigma \circ \nu о \mu \iota \alpha)$ dos cidadãos perante a lei, tal qual o concebido em 508-507 a.C, por Clístenes (Aristóteles, 2000; Jones, 1997), embora não se aplicasse o todos os humanos, pois estavam excluídos os escravos e as mulheres.

$\mathrm{Na}$ Teogonia, Hesíodo descreve o nascimento de Nereu, o Ancião do Mar (Hesíodo, 1995),

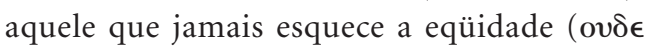
$\theta \epsilon \mu \iota \sigma \tau \epsilon \omega \nu \lambda \eta \theta \epsilon \tau \alpha \iota)$, porque só conhece pensamentos justos e benignos ( $\delta \iota \kappa \alpha \iota \alpha \kappa \alpha \iota \eta \pi \iota \alpha)$, razão pela qual era celebrado em inúmeros procedimentos judiciais até por volta do século VI
a.C. (Detienne, 1988). A temática recorre em Os trabalhos e os dias, em que, na exposição do mito das Cinco Idades, Hesíodo manifesta sua conhecida fórmula de oposição entre $\delta\llcorner\kappa \eta$ (justiça) e a desmesura (Siqueira-Batista, 2003):

Ouve a díke, a justiça, e não deixe crescer

A hýbris, o descomedimento (Hesíodo, 1996: verso 213).

Considerações acerca da justiça estão presentes, igualmente, nas tragédias gregas e nos fragmentos de vários filósofos pré-socráticos como Anaximandro, Heráclito, Empédocles e Demócrito, apenas para mencionar alguns deles (Bornheim, 1999; Kirk et al., 1994; Siqueira-Batista, 2003). Nestas concepções pode ser identificado, como fio condutor, a prerrogativa de manutenção da ordem, uma harmonia de caráter universal, regendo o cosmo (como natureza, $\phi v \sigma \iota \varsigma)$, o homem e a cidade, caracterizando, assim, uma justiça cósmica (Ferrater Mora, 1994). Críticas dirigidas a estas idéias partiram dos sofistas, os quais compreendiam a justiça como convenção, esvaziando, assim, seu caráter natural, universal e imutável (Reale, 1999a).

Uma recuperação do valor objetivo da justiça é realizada por Platão, tornando-a o eixo de sustentação da ética e da política (Reale, 1999b). Nos diálogos Górgias e A República há especial preocupação com o tema, estabelecendo-se que justo é cumprir o que é próprio de cada um (Platão, 1987; 1992; Siqueira-Batista \& Schramm, 2004). Ademais, o pensador de Atenas estipula que se uma sociedade é justa há justiça para todos os seus pertencentes (Platão, 1987).

Muito da teorização de Aristóteles sobre a justiça é devedora de Platão. Tal qual o ateniense, o filósofo de Estagira coloca a justiça como princípio primeiro ou virtude arquitetônica, para a constituição de qualquer sociedade ordenada e sem conflitos, pressuposto primevo para a realização de uma vida feliz (Aristóteles, 1985; Schramm, 2003). Em A política, Livro II, 2, 10, escreveu: [...] a justiça é o vínculo dos homens, nos Estados; porque a administração da justiça, que é a determinação daquilo que é justo, é o princípio da ordem em uma sociedade politica (Aristóteles, 2000).

Sem embargo, Aristóteles introduz noções capitais que se mantêm atuais ainda hoje. Divide a justiça em 1) comutativa (corretiva ou retificativa), a qual regula as relações entre os cidadãos, e 2) distributiva, que consiste na distribuição eqüitativa - de honrarias, fortuna e to- 
das as demais coisas - entre os que compõem a sociedade, ou seja, podendo ocorrer participação igual ou desigual na dependência das circunstâncias (Aristóteles, 1985). Assim, pode-se dizer que o estagirita situa a justiça no horizonte da eqüidade $(\epsilon \pi \iota \epsilon \iota \kappa \epsilon \iota \alpha)$, como o demarcado no Livro V da Ética a Nicômaco:

[...] a mesma igualdade será observada entre as pessoas e entre as coisas envolvidas, pois do mesmo modo que as últimas (as coisas envolvidas) são relacionadas entre si, as primeiras também o são. Se as pessoas não são iguais, não receberão coisas iguais; mas isso é origem de disputas e queixas (como quando iguais têm e recebem partes desiguais, ou quando desiguais recebem partes iguais) (Aristóteles, 1985: passo 1131 a21-26; grifo nosso).

A partir dessa citação, pode-se perceber, claramente, uma consubstancial tensão entre a justiça como igualdade e como eqüidade, ou seja, em certa medida um tratamento desigual poderá ser deflagrado para corrigir injustiças. Esta problemática é retomada por São Tomás de Aquino - que, no "rastro" de Aristóteles, concebe três classes de justiça (comutativa, distributiva e geral) em sua Suma teológica (19441961) - e Gottfried W. Leibniz, para o qual há também três subdivisões da justiça: 1 ) respeito ao direito estrito, 2) eqüidade para o bem da comunidade e 3) piedade, de inspiração cristã, considerada sua modalidade universal (Leibniz, 1989).

A mencionada separação sofista entre natural e político é recuperada por Thomas Hobbes, ao distinguir o estado natural (egoísta e injusto) e social (altruísta e justo) do homem. Criticando Aristóteles, Hobbes - um defensor do despotismo político - expõe que a vida humana em sociedade não é natural, como no caso das térmitas, mas, sim, artificial e motivada pelo desejo universal de autopreservação. Este anseio seria o fundamento que torna iguais todos os homens (Hobbes, 2000). Jean-Jacques Rousseau, para quem, ao contrário, o homem é naturalmente livre e bom, reconhece também que todos os homens são iguais, comungando a vida em comunidade graças a um pacto estabelecido entre povo e governantes - o contrato social (Rousseau, 1989).

Mantendo-se neste mesmo liame de consenso - prerrogativa das maiorias -, David Hume concebe a justiça como subserviente ao interesse de todos os membros da sociedade, em uma delimitação material, no sentido de se fundar em uma realidade concreta - a utilida- de de todos os cidadãos ou o maior bem possível (Hume,1968). Emerge, assim, um diáfano âmago utilitarista, o qual viria ser aprofundado posteriormente por teóricos como Jeremy Bentham (1970) e John Stuart Mill (2000).

À idéia utilitarista de justiça se dirige a pesada crítica de John Rawls. A teoria de justiça formulada por este pensador liberal americano segue como uma das mais importantes tentativas, no século 20, de síntese entre os valores cardinais da tradição política ocidental - liberdade, igualdade, solidariedade e respeito - em uma visão normativa com legítimas raízes liberais (Vita, 1999a).

Rawls se contrapõe aos modelos teleológicos em filosofia moral e política - como os utilitarismos e as éticas hedonistas -, na medida em que estes concebem o bem independentemente do justo. De outro modo, entende que a justiça, longe de ser o resultado dos "interesses" de todos, ou da maioria, é sim o pressuposto deontológico - para a lídima coalizão dos anseios comuns. Neste aspecto, o filósofo se aproxima de Immanuel Kant: concebe todo um formalismo para articular regras (procedimentos) e práticas (instituições), partindo das primeiras em direção a estas últimas (Oliveira, 2003). Ademais, o lugar de destaque dado à liberdade neste modelo eqüitativo é também tributário de Kant, uma vez que é a partir desta que se deriva o princípio universal de justiça kantiano (Pascal, 1996).

A democracia liberal rawlsiana se sustenta, em termos ideais, sobre as concepções de 1) posição original (original position), situação hipotética na qual as pessoas livres e iguais escolhem, sob um "véu da ignorância" - ou seja, movidos pelo desinteresse recíproco resultante do fato de nenhum dos participantes conhecer de antemão qual posição ocupará ao final do processo - os princípios de justiça que devem governar a estrutura básica da sociedade, e 2) sociedade bem-ordenada (well-ordered society), a qual é regulada por uma concepção política e pública de justiça, aceita por todos os cidadãos, nos termos eqüitativos de cooperação social (Oliveira, 1999; Rawls, 1997; Schramm 2000a).

Quais seriam, na formulação de Rawls, os princípios de uma sociedade liberal-democrática justa? A enunciação feita pelo filósofo traz o seguinte conteúdo (Rawls, 1997; 1992; 1999): 1) cada pessoa tem o mesmo direito a um esquema plenamente apropriado de liberdades básicas iguais (direitos de votar e de ocupar um cargo público, de pensamento e expressão, de 
integridade pessoal, à propriedade privada e de proteção contra prisão arbitrária, principalmente) desde que seja compatível com a garantia de um esquema idêntico para todos; e

2) as desigualdades sociais e econômicas somente se justificam se dois requisitos forem contemplados: (a) se estiverem vinculadas a posições e cargos abertos a todos em condições de igualdade de oportunidades; e b) devem ser estabelecidas para o maior benefício possível dos membros da sociedade que se encontrarem na posição mais desfavorável.

Destarte, em sua teorização há o desejo de equacionar maior justiça social (em um sentido "compensatório"), por um lado, e de preservar a democracia liberal e o sistema de mercado capitalista, por outro (Schramm, 2000b), caracterizando assim a eqüidade (fairness). As questões fundamentais se voltariam, então, para o "tratamento" das iniqüidades, no bojo da plena garantia das liberdades: $O$ primeiro problema da justiça é determinar os princípios para regular as desigualdades e ajustar os efeitos profundos e de longa duração das contingências sociais, naturais e históricas, particularmente porque, combinada com as desigualdades, essas contingências, quando abandonadas a si mesmas, são profundamente díspares com relação à liberdade e a igualdade apropriadas para uma sociedade bem-ordenada (Rawls, 1999).

Os três princípios - a igual liberdade (1), igualdade eqüitativa de oportunidade (2a) e diferença ou justiça maximin (2b), respectivamente - estão locados por ordem de primazia, denotando a mencionada ascendência do justo sobre o bem (Oliveira, 2003). Rawls admite a justeza de algumas formas de desigualdade (princípios $2 \mathrm{a}$ e $2 \mathrm{~b}$ ), refutando o igualitarismo social - tal qual o pensado, por exemplo, para os estados socialistas (Genro, 1998). Argumenta, assim, que tudo aquilo que escape a uma distribuição igual de bens primários - (i) liberdades básicas iguais, (ii) livre escolha de ocupação, (iii) acesso a cargos e posições de responsabilidade nas instituições políticas e econômicas da estrutura básica da sociedade, (iv) renda e riqueza e (v) bases sociais do auto-respeito - não pode ser justificado em termos de paridade (Rawls, 1996; Ribeiro, 2003; Vita, 1999a). Torna-se preferível, baseado nesta premissa, um arranjo institucional que garanta uma maior porção em termos absolutos, ainda que não igual, de bens primários para todos, do que um outro no qual uma igualdade de resultados é assegurada à custa de reduzir as esperanças de todos (Vita, 1999a) - eis uma outra formulação possível para o princípio da diferença.

De formas obviamente distintas, as igualdades traçadas por Aristóteles e Rawls são permissivas à diferença. Se a justiça do estagirita parte da desigualdade - em última análise, da diferença - para alcançar a igualdade por meio de um procedimento compensatório, em Rawls a desigualdade poderia se sobrepor a uma igualdade plena para benefício da coletividade - razão pela qual alguns críticos, como Robert Nozick (1991), acusam de insuficiente o igualitarismo rawlsiano.

Esta é uma questão-chave, uma vez que grande parte do debate acerca da paridade e da justiça repousa, em última análise, sobre como tornar iguais "coisas" - no caso, pessoas - que são intrinsecamente diferentes, algo instituído nas próprias origens do Espírito helênico ( $\mathrm{Si}$ queira-Batista, 2003). Tal é a percepção do filósofo Henrique C. de Lima Vaz: A invenção grega do político torna-se justamente o gesto instaurador do Ocidente como idéia civilizatória na medida em que dá forma histórica à dialética da igualdade na diferença como dialética própria do ser político. Ela assegura ao homem, ser social, essa forma superior de igualdade que o eleva da particularidade das diferenças individuais à universalidade concreta do ser-reconhecido no universo ético da politéia, ou no reino das leis (Lima Vaz, 2002; grifo do autor).

Profundas contradições deste ideal foram apontados por filósofos no século 20. Wittgenstein, por exemplo, criticou a obsessão pelas generalidades por parte dos pensadores da tradição ocidental - afinal, a detecção de semelhanças não pressupõe a existência de gerais -, reafirmando a diversidade e a diferença (Wittgenstein, 1987). Gilles Deleuze, ao contrário, discute a diferença de si mesma, um estado de determinação como distinção unilateral, não mediatizada, desenhando novos contornos para o problema da diferença (Deleuze, 1981).

O horizonte empírico anteriormente matizado - as desigualdades em saúde - parece ratificar a aporia conceitual igualdade-diferença, não passível de simples resolução dialética. A teoria de justiça rawlsiana aponta nesta direção, mas a igualdade é de difícil equacionamento, uma vez que se determina, a priori e de forma inflexível, aquilo que deve ser o motivo do igualitarismo - no caso os bens primários, assim considerados segundo a ótica liberal (mas não, provavelmente, por uma perspectiva marxista, por exemplo). Este posicionamento 
tem como conseqüência a possibilidade de se "igualar" coisas não relevantes para uma parcela de indivíduos (por exemplo, uma pessoa pode discordar que votar seja realmente um bem primário), gerando assim desigualdades mais incômodas e profundas que as "originárias". Deste modo, há necessidade de se traçarem díspares fronteiras para a discussão da justiça - no presente caso, articulada à questão sanitária - a partir de novas modalidades de incorporação da diferença no âmago da igualdade. Neste limiar, pode ser útil a contribuição de Sen.

O que se pode fazer...

Capacidades e funcionamentos: a igualdade complexa de Amartya Sen

A obra do economista Amartya Kumar Sen tem a marca de um profundo incômodo diante das desigualdades sociais. Desde seu "florescimento" intelectual na década de 1950 , o pensador indiano tem se dedicado aos estudos sobre teoria da escolha social e economia do bem-estar, áreas nas quais tornou-se autoridade mundial. Seus escritos vêm influenciando as análises e os programas das Organizações das Nações Unidas e do Banco Mundial. A partir dos anos 90 participa da preparação do Relatório de Desenvolvimento Humano e, em 1993, foi um dos elaboradores do Índice de Desenvolvimento $\mathrm{Hu}$ mano (IDH). Por suas contribuições à economia do bem-estar foi agraciado com o Prêmio Nobel de Economia em 1998.

Em uma das suas mais importantes obras, Desigualdade reexaminada, Sen retoma uma antiga questão (Sen, 1980) - igualdade de quê? - para enfrentar o problema da desigualdade (Sen, 2001). Qual seria a razão para tal questionamento? A igualdade, se considerada em termos absolutos, representa uma abstração impossível de ser estendida ao cotidiano, haja vista a infinita diversidade humana em todos os horizontes da existência. Assim, concepções de justiça que se baseiam, pura e simplesmente, em uma pretensa igualdade plena estariam condenadas ao fracasso em suas próprias origens, o que implica, como visto anteriormente, a necessidade de se integrar a diferença à discussão, tornando assim factível a "escolha" por uma (ou algumas) dimensões para manifestação da igualdade, como o demarcado por Vita: Nenhuma concepção de igualdade distributiva pode tornar as pessoas iguais em todas essas dimensões ao mesmo tempo, das circunstâncias so- ciais ao nível de realização das preferências e valores de cada qual. A opção por igualizá-las em uma dessas dimensões implica aceitar que elas sejam desiguais em outra (Vita, 1999b).

São várias as respostas possíveis para esta indagação. Poder-se-iam divisar os igualitaristas clássicos, que insistem sobre os pesos iguais para as utilidades de todos; os igualitaristas libertários, que preconizam a liberdade e o respeito a uma classe inteira de direitos e liberdades; os igualitaristas de renda, cuja paridade repousaria em rendas idênticas e os igualitaristas de bem-estar, os quais pedem um mesmo nível de bem-estar (Sen, 2001). Estas disparidades na abordagem da igualdade refletem "disputas" nas diferentes correntes de pensamento em relação ao que é considerado central para o exercício em sociedade - e, por conta disto, deverá ser "igualado" - determinando, de outro modo, o que será aceito como desigualdade.

Destarte, a "síntese" igualdade-diferença é, em geral, arbitrária, sem levar em consideração as perspectivas de vida dos próprios interessados, na qualidade de sujeitos autônomos, o que pode ser apontado como a grande deficiência ou limitação destas formulações (como o anteriormente discutido em relação a Rawls). É precisamente neste aspecto que o modelo de Sen se coloca como relevante diferencial, ao preconizar uma igualdade (complexa) de oportunidades, a partir da caracterização e delimitação das capacidades e dos funcionamentos, nos seguintes termos:

(1) As capacidades (capabilities) se referem à liberdade efetiva que um indivíduo tem de escolher diferentes tipos de vida - entre as alternativas possíveis -, tornando factível a opção por realizar distintos grupos de funcionamentos, ou seja: capacidade é, portanto, um conjunto de vetores de funcionamentos, refletindo a liberdade da pessoa para levar um tipo de vida ou outro. Tal como o assim chamado "conjunto orçamentário" no espaço de mercadorias representa a liberdade de uma pessoa para comprar pacotes de mercadorias, o "conjunto capacitário", no espaço de funcionamentos, [representa] a liberdade da pessoa para escolher dentre vidas possíveis (Sen, 2001).

A capacidade (capability) é assim estritamente relacionada a alguma(s) preferência(s), pela(s) qual(is) se faz uma livre opção, alicerçada na autonomia do sujeito (Schramm, 1998a; Sen, 1985a).

(2) Os funcionamentos representam partes do estado de uma pessoa - em particular, as coisas que logra fazer um vivente (Sen, 1996). Estes 
podem variar desde os mais simples - como estar bem nutrido, educado e instruído, livre de doenças evitáveis e da morte prematura -, até os mais complexos - como ter auto-respeito, ser capaz de tomar parte na vida em comunidade, estar feliz, entre outros (Sen, 2001). Eles dão, assim, uma medida dos elementos constituintes do bem-estar para aquela pessoa.

A abordagem com base nas capacidades e funcionamentos representa um grande avanço no debate sobre igualdade e justiça, pois representa uma visão dos propósitos humanos não detida no espaço do "ter", inscrevendo-se, outrossim, no espaço do "fazer” e do "ser” (Kerstenetzky, 2000), abolindo a determinação heterônoma do que deve ser igualado, passando a voz de escolha ao titular da própria existência; possibilitando, em suma, o empoderamento sobre seu caminho. Há, deste modo, a integração de uma saudável distribuição de meios plurais para a realização de uma multiplicidade de anseios e valores caros para aquele que detém a escolha.

Este traz um horizonte bem distante tanto da perspectiva welfarista - na medida em que dá um lugar de destaque à responsabilidade individual (Vita, 1999b) -, quanto utilitarista, ao criticar a possibilidade de dissonância cognitiva nas distorções dos desejos nos contextos em que não é facultada a livre escolha: os fracassados e os oprimidos acabam por perder a coragem de desejar coisas que outros, mais favoravelmente tratados pela sociedade, desejam confiantemente. A ausência de desejo por coisas além dos meios de que uma pessoa dispõe pode refletir não uma valoração deficiente por parte dela, mas apenas uma ausência de esperança, e o medo da inevitável frustração. O fracassado enfrenta as desigualdades sociais ajustando seus desejos às suas possibilidades (Sen, 1990).

A igualdade se complexifica no repertório teórico de Sen, abrindo a possibilidade de respeito às escolhas pessoais autênticas - não "turvadas" pelas desigualdades impingidas pelas assimetrias da realidade social (Kerstenetzky, 2000). Há igualmente um afastamento dos igualitarismos anteriormente apresentados, como no caso da comparação entre os "recortes" por renda ou pelas capacidades: [...] rendas iguais podem ainda deixar bastante desiguais nosso potencial de fazer o que podemos valorizar fazer. Um pessoa incapacitada não pode realizar funcionamentos do modo que uma pessoa com o "corpo hábil" pode, ainda que ambas tenham exatamente a mesma renda (Sen, 2001).
Obviamente, este não é um argumento contrário à redistribuição de renda, mas tão somente a constatação do quão prejudicial pode ser a restrição de se igualar apenas este quesito, desconsiderando outros campos relevantes da vida.

Compreende-se, com base nestas disposições, que são as capacidades os elementos a serem igualados no sentido de permitir sua igual expressão. Delineia-se destarte uma elegante síntese entre igualdade e liberdade, instâncias colocadas em pólos opostos em muitas interfaces das discussões sobre a justiça. Sen consegue demonstrar que uma "vida boa" é compreendida como pressupondo escolhas genuínas, de modo que ninguém seja obrigado a viver de alguma forma específica, por mais rica que possa ser em outros aspectos (Sen, 1985b). Assim: [...] a liberdade pode ser vista como intrinsecamente importante para uma boa estrutura social. Uma boa sociedade também é, nesta concepção, uma sociedade de liberdade (Sen, 2001).

Esta visão se aproxima, de algum modo, da concepção marxista e engeliana de liberdade, como o transcrito da Ideologia alemã: [uma sociedade liberta possibilitaria] tornar possivel que eu fizesse uma coisa hoje e outra amanhã, caçasse pela manhã, pescasse à tarde, cuidasse do gado à noite, tecesse críticas após o jantar, tal como pretendesse, sem nunca me tornar um caçador, pescador, pastor ou crítico (Marx \& Engels, 1947).

Este igualitarismo de oportunidades - autêntica igualdade complexa - tem profundas implicações no âmbito da saúde. Nenhuma concepção de justiça social de base eqüitativa pode desconsiderar o gigantesco papel da saúde na existência humana, tanto no campo das possibilidades de uma pessoa alcançar uma vida livre de enfermidades, quanto da ampliação das capacidades e funcionamentos, caso goze de boa saúde (Sen, 2002). Assim, esta deve ser encarada como um dos pressupostos fundamentais para a composição de qualquer idéia de justiça.

É crescente a conscientização de que as desigualdades entre ricos e pobres, em relação à saúde - mas não apenas neste ponto - são injustas, uma vez que as disparidades sociais correspondem, obviamente, às limitações e às oportunidades díspares que tem um e outro grupo (Wagstaff, 2002). No atual contexto explicitado na primeira seção deste ensaio -, pôde-se delimitar o quanto a pobreza e a desigualdade concorrem para reduzir o nível de saúde de um povo (ou de um grupo), e vice- 
versa - moléstia como mantenedora de mais miséria. Esta retroalimentação espúria denota uma total ausência de liberdade - (in)capacidade - para realizar os funcionamentos mais elementares para um ser humano, tais como se alimentar adequadamente, possuir condições dignas de moradia, ter direito ao trabalho, usufruir de horas de lazer, entre outros. Não há escolha entre comer e não comer - como no caso de alguém que optasse pelo jejum por motivos religiosos - ou entre conviver ou não com a violência urbana dos grandes centros. De fato, a "imposição" das condições sócio-ambientais é um impeditivo para qualquer possibilidade de se escolher - e alcançar - circunstâncias que promovam o bem-estar.

O que delimita a iniqüidade neste status quo é a falta de oportunidade, muitas vezes conseqüente à exclusão social, para livres decisões. Sucumbir a uma moléstia por motivos socioeconômicos - desnutrição infantil pela falta de se ter o que comer - é absolutamente contrastante com o adoecimento secundário a uma eleição pessoal, por mais intrincada que seja ela - como adquirir infecção pelo vírus da imunodeficiência humana (HIV) em decorrência da não utilização voluntária de preservativos.

Entre o princípio de que a saúde seja um direito de todos - como reza a Constituição brasileira (Brasil, 2000) - e a garantia de seu cumprimento, interpõe-se uma distância considerável, visto que não basta preconizar as mesmas bases sanitárias para toda sociedade, uma vez que as demandas pessoais são deveras abrangentes, podendo, neste caso, se produzir um aguçamento das disparidades. Um bom exemplo disto pôde ser constatado na investigação de Victora e colaboradores (1989), que descreveram, no Ceará, os resultados de um programa destinado à redução das desigualdades sanitárias. Foram observadas consideráveis melhorias nos níveis de utilização dos serviços de saúde, na cobertura vacinal e no uso da reidratação oral nas crianças mais pobres, ainda que tenha ocorrido agravamento das desigualdades nestas mesmas variáveis, em comparação com os infantes de famílias mais abastadas.

Tratar diferentemente - no que se refere aos recursos dispensados na saúde - os distintos grupos e pessoas, pode representar a melhor forma de se alcançar uma sociedade mais justa, o que, em última análise, é um legado aristotélico (Aristóteles, 1985; Sen, 2001), tal qual o comentado por Sen: [...] as desigualdades, inclusi- ve na atenção sanitária e não apenas no alcance da saúde, também podem ser importantes para a justiça social e a eqüidade na saúde [...] Suponhamos que as pessoas $A$ e B têm exatamente as mesmas predisposições em relação à saúde, entre elas a mesma propensão para uma enfermidade particularmente dolorosa. Mas A é muito rico e consegue curar ou suprimir completamente sua doença com algum tratamento médico caro, enquanto $B$, que é pobre, não pode pagar tal tratamento, pelo que sofre muito com a moléstia. Aqui há uma clara desigualdade na saúde. [...] os recursos usados para curar o rico A poderiam ter sido usados para proporcionar algum alivio a ambos [...] (Sen, 2002).

Na situação acima descrita, a pessoa B (pobre) iria requerer maiores recursos para controle do seu mal, em relação à pessoa $\mathrm{A}$ (abastada). A desigual distribuição de renda - por uma política de saúde, por exemplo - tornar-se-ia o fator capaz de aproximar as capacidades para a escolha do funcionamento "estar livre da doença e da dor". Uma sociedade em que se almeje a justiça deverá, necessariamente, desenvolver mecanismos compensatórios para seus membros vitimados por desigualdades das quais não podem ser responsabilizados, tais como políticas equânimes de alocação de recursos (Giovanella et al., 2002; Schramm, 1998b), capazes de se contrapor às históricas contingências de iniqüidade, miséria e exclusão que forneceram o arcabouço para a (des)estruturação da sociedade brasileira (Alencar et al., 1988; Barros et al., 2000; Siqueira-Batista, 1996).

Mas este não é o único aspecto de relevância. A extensão da eqüidade em saúde não se limita unicamente à questão sanitária, possuindo uma significativa abrangência, capaz de perpassar acordos sociais, distribuição econômica e o legítimo espectro da liberdade (Schramm \& Kottow, 2001; Sen, 2002). Compreender as desigualdades em saúde e suas relações com outros campos em que se manifesta a disparidade - tal qual o comentado na primeira parte deste manuscrito - torna-se capital para o equacionamento e a proposta de medidas para reduzir os desníveis existentes. Um enfoque adequado da política de saúde deve ter em conta não apenas os fatores sociais e econômicos, mas também uma variedade de elementos, como as predisposições biológicas, as (dis)capacidades pessoais, as características antropológicas e culturais, os riscos epidemiológicos, as influências ambientais e climáticas, entre outros, possibilitando a composição do tecido, multifato- 
rial, do intrincado processo saúde-doença, à luz da tão ansiada eqüidade social.

\section{Ponderações finais}

A questão da justiça guarda um lugar de destaque nos aspectos relacionados à saúde. Os últimos anos trouxeram debates especialmente fecundos sobre a eqüidade sanitária, havendo, no caso brasileiro, o correspondente político de desenho e implantação do SUS. Mas, há muito ainda por ser realizado até que possa atingir um patamar mínimo de justiça social no País (Kerstenetzky, 2000; Magalhães, 2001; Schramm \& Kottow, 2001).

Retomando os três pontos elencados na Introdução - acesso universal à saúde, igualdade das pessoas e, compondo ambos, a premência de um ideal de justiça - no fulcro de uma leitura atenta das concepções de Amartya Sen, transparecem alguns elementos centrais que podem ser coligidos nos seguintes aspectos:

1) $\mathrm{O}$ acesso universal à saúde é um direito constitucional brasileiro que necessita ser tornado fato, a partir da elaboração e execução de políticas públicas que minimizem as distâncias entre as capacidades das pessoas, permitindo a eleição dos funcionamentos essenciais por aqueles de direito - os titulares da existência (Magalhães, 2002; Sen, 1987; 2001).

2) A maximização das demandas é realmente um problema, mas a tão apontada escassez de recursos não é o grande limitador na sociedade brasileira, como vem sendo demonstrado em diversos trabalhos (Barros et al., 2000; Rocha, 2003); uma vez mais é a concentração abusiva de renda - muito mais que sua falta - que torna o acesso aos funcionamentos tão difícil, para não dizer impossível, a uma parcela substantiva do povo brasileiro, devendo, assim, tais disparidades se tornarem alvo das políticas de focalização de recursos para saúde - obviamente, em um contexto mais amplo de redistribuição de renda, à luz das discrepâncias entre as capacidades (Kottow, 2000; Sen, 2002).

Estes dois quesitos iniciais mostram a pertinência de se recompor as tensões no binômio universalização-focalização, tão em voga nos debates hodiernos sobre a alocação de subsídios em saúde (Ribeiro, 2002; Schütz, 2002). Neste contexto, retomando a análise:

3) A reorientação dos recursos a todos (universalização), mas de forma diferenciada (focalização), permitindo acesso global à saúde, re- presentaria um gigantesco passo em direção à maior paridade e à menor exclusão; uma vez mais a "fórmula" aristotélico-seniana de justa distribuição desigual se mostra como melhor caminho para a maior eqüidade em saúde (Aristóteles, 1985; Berti, 1998; Kerstenetzky, 1999; Lucchese, 2003; Ribeiro, 2002; Schütz, 2002; Sen, 1992).

4) As três delimitações acima acenam para o ideal de justiça, a ser buscado no campo conceitual tecido na interseção Rawls-Sen, na medida em que este último não propõe uma teoria alternativa de justiça em relação a Rawls, mas, sim, uma concepção de justiça distributiva em sentido estrito (Vita, 1999b), incorporando elementos rawlsianos e aristotélicos, elegantemente articulados em uma concepção mais ampla aqui tratada como igualdade complexa. A crítica do indiano - por nós endossa$\mathrm{da}$, a despeito das esclarecedoras considerações de Vita sobre a teoria rawlsiana (1999b) - refere-se à imutabilidade dos bens primários - minimizando as variações interindividuais - e à localização "errônea" do espaço avaliatório da concepção de Rawls, na medida em que a preocupação básica do debate não é com os bens de per se, mas com as pessoas que estão vivendo em sociedade (Sen, 2001). Uma tal concepção de justiça, capaz de equalizar belamente igualdade e liberdade, é o que se tem de melhor, ao menos por ora, para o direcionamento das discussões - teóricas e políticas - no "espinhoso" campo da saúde.

Pode parecer que o legado intelectual de Amartya Sen mostrar-se-ia suficiente para delimitar as relações entre saúde, justiça e iniqüidade. Ledo engano. Além de ser, como toda boa teoria, insuficiente para abarcar a multidimensional realidade, acolher a concepção de capacidades e funcionamentos de Sen pressupõe uma radical transformação social, a qual inclui o âmbito da saúde, mas é em si mesma capaz de alcançar horizontes muito mais amplos, "quase" revolucionários. Se é factível ou não, permanece como indagação sem resposta. Mas, guardando a agudeza do Espírito filosófico, vale a pena instigar o germe da dúvida, embrionário na Teogonia de um certo Hesíodo, ao matizar a emergência da ordem a partir do caos, lampejo primevo, lídima potência deflagradora para as veredas permissivas ao desabrochar da justiça... 


\section{Colaboradores}

R Siqueira-Batista e FR Schramm trabalharam a quatro mãos, como hoplitas, na concepção do presente manuscrito; este representa, por conseguinte, um genuíno magma das contribuições de ambos os autores.

\section{Referências bibliográficas}

Alencar F, Carpi L \& Ribeiro MV 1988. História da sociedade brasileira. (3a ed.). Ao Livro Técnico, Rio de Janeiro.

Aristóteles 1985. Ética a Nicômaco. Tradução de Mário da Gama Kury. Ed. Universidade de Brasília, Brasília.

Aristóteles 2000. Constituição de Atenas. Tradução de Therezinha M. Deutsch. Nova Cultural, São Paulo.

Azevedo A 1997. O cortiço. (30ạ ed.). Ática, São Paulo.

Barros RP, Henriques R \& Mendonça R 2000. Desigualdade no Brasil: retrato de uma estabilidade inaceitável. Revista Brasileira de Ciências Sociais 15(42):123142.

Bentham J 1970. An introduction to the principles of moral and legislation. Editado por JH Burns e HLA Hart. Athlone Press, Londres.

Berti E 1998. As razões de Aristóteles. Tradução de Dion Davi Macedo. Loyola, São Paulo.

Bornheim GA 1999. Os filósofos pré-socráticos. (13a ed.). Cultrix, São Paulo.

Brito Quintana P 2000. El impacto de las reformas del sector de la salud sobre los recursos humanos y la gestión laboral. Pan American Journal of Public Health 8(1/2):43-52.

Brasil 2000. Constituição da República Federativa do Brasil. Ed. Revista dos Tribunais, São Paulo.

Castellanos PL 1997. Epidemiologia, salud pública, situación de salud y condiciones de vida: consideraciones conceptuales, pp. 31-75. In RB Barata (org.). Condições de vida e situação de saúde. Abrasco, Rio de Janeiro.

Cordeiro H 2001. Descentralização, universalidade e eqüidade nas reformas da saúde. Ciência e Saúde Coletiva 6(2):319-328.

Deleuze G 1981. Différence et répétition. (4a ed.) Presses Universitaires de France, Paris.

Detienne M 1988. Os mestres da verdade na Grécia arcaica. Jorge Zahar Ed. Rio de Janeiro.

Engel DC, Vergara TRC \& Almeida RMM 2001. Neoplasias relacionadas à Aids, pp. 887-895. In R Siqueira-Batista, AP Gomes, RP Igreja \& DW Huggins (orgs.). Medicina tropical. Abordagem atual das doenças infecciosas e parasitárias. Ed. Cultura Médica, Rio de Janeiro.

Ferrater Mora J 1994. Dicionário de Filosofia. Justiça (verbete). Ariel, Barcelona, Tomo II.

Fleury S 1995. Iniqüidades nas políticas de saúde: o caso da América Latina. Revista de Saúde Pública 29(3): 243-250.

Furtado C 1974. O mito do desenvolvimento econômico. Paz e Terra, Rio de Janeiro.

Galeano E 1994. As veias abertas da América Latina. Tradução de Galeano de Freitas. (36a ed.). Paz e Terra, Rio de Janeiro.
Genro T 1998. O Estado e o manifesto comunista, pp. 121-138. In CN Coutinho (org.). O manifesto do Partido Comunista 150 anos depois. Contraponto, Rio de Janeiro.

Giovanella L, Vaitsman J, Escorel S, Magalhães R \& Costa NR 2002. Health and inequality: institutions and public policies in the 21st century. Pan American Journal Of Public Health 11(5/6):466-470.

Girotto GC, Lobo-Magalhães L \& Pereira LAL 2003. Diarréias infecciosas, pp. 61-63. In R Siqueira-Batista et al. (orgs.). Manual de Infectologia. Ed. Revinter, Rio de Janeiro.

Hesíodo 1995. Teogonia: a origem dos deuses. Estudo e Tradução de J.A.A. Torrano. (3a ed.). Iluminuras, São Paulo.

Hesíodo 1996. Os trabalhos e os dias. Tradução de Mary de Carvalho Neves Lafer. 3a ed. Iluminuras, São Paulo.

Hobbes T 2000. Leviatã. Tradução de João Paulo Monteiro e Maria Beatriz Nizza da Silva. Nova Cultural, São Paulo.

Hume D 1968. A treatise of human nature. Clarendon Press, Oxford.

Jones 1997. O mundo de Atenas. Uma introdução à cultura clássica ateniense. Tradução de Ana Lia de Almeida Prado. Martins Fontes, São Paulo.

Kant I 1960. Fundamentação da metafísica dos costumes. Tradução de Paulo Quintela. Edições 70, Lisboa.

Kerstenetzky CL 1999. Desigualdades justas e igualdade complexa. Lua Nova 47(9):4-26.

Kerstenetzky CL 2000. Desigualdade e pobreza: lições de Sen. Revista Brasileira de Ciências Sociais 15(2):113122.

Kirk GS, Raven JE \& Schofield M 1994. Os filósofos présocráticos: história crítica com seleção de textos. Tradução de Carlos Alberto Louro Fonseca. Fundação Calouste Gulbenkian, Lisboa.

Kottow M 2000. Bioética e política de recurso em saúde, pp. 67-75. In V Garrafa \& SIF Costa (orgs.). Bioética no século XXI. Universidade de Brasília, Brasília.

Labra ME 2001. Política e saúde no Chile e no Brasil. Contribuições para uma comparação. Ciência e Saúde Coletiva 6(2):361-376

Lavy V, Strauss J, Thomas D \& de Vreyer P 1996. Quality of care, survival and health outcomes in Ghana. Journal of Health Economy 15(2):333-357.

Leibniz GW 1989. Political writtings. Tradução de P. Riley. Cambridge University Press, Cambridge.

Lima Vaz HC 2002. Ética e direito. Landy-Loyola, São Paulo.

Lucchese R 2003. Eqüidade na gestão descentralizada do SUS: desafios para a redução das desigualdades em saúde. Ciência e Saúde Coletiva 8(2):439-448.

Macedo AC, Paim JS, Silva, Lígia MV \& Costa MCN 2001. 
Violência e desigualdade social: mortalidade por homicídios e condições de vida em Salvador, Brasil. Revista de Saúde Pública 35(6):515-522.

Magalhães MDB 1997. A lógica da suspeição: sobre os aparelhos repressivos à época da ditadura militar no Brasil. Revista Brasileira de História 17(34):203-220.

Magalhães R 2001. Integração, exclusão e solidariedade no debate contemporâneo sobre as políticas sociais. Cadernos de Saúde Pública 17(3):569-579.

Magalhães R 2002. Enfrentando a pobreza, reconstruindo vínculos sociais: as lições da Ação da Cidadania contra a fome, a miséria e pela vida. Cadernos de Saúde Pública 18(supl.):121-132.

Marx K \& Engels F 1947. The German ideology. International Publishers, Nova York.

Mill JS 2000. O utilitarismo. Tradução e introdução de Alexandre Braga Masella. Iluminuras, São Paulo.

Minayo MCS 1998. A autoviolência, objeto da sociologia e problema de saúde pública. Cadernos de Saúde Pública 14(2):421-428.

Minayo MCS \& Minayo M 1999. Os muitos brasis. Saúde da população na década de 80. Hucitec, São Paulo.

Minayo MCS 2003. Violência contra idosos: relevância para um velho problema. Cadernos de Saúde Pública 19(3):783-791.

Nascimento EP 1994. A exclusão social na França e no Brasil: situações (aparentemente) invertidas, resultado (quase) similares?, pp. 289-303. In E Diniz, JSL Lopes \& R Prandi (orgs.). O Brasil no rastro da crise. Hucitec, São Paulo.

Njaine K \& Minayo MCS 2002. Análise do discurso da imprensa sobre rebeliões de jovens infratores em regime de privação de liberdade. Ciência \& Saúde Coletiva 7(2):285-297.

Nozick 1991. Anarquia, Estado e utopia. Tradução de Ruy Jungnann. Jorge Zahar, Rio de Janeiro.

Oliveira N 1999. Tractatus ethico-politicus-genealogia do ethos moderno. Edipucrs, Porto Alegre.

Oliveira N 2003. Rawls. Jorge Zahar, Rio de Janeiro.

Paim JS \& Costa MCN 1993. Decréscimo e desigualdade da mortalidade infantil, Salvador, 1980-1988. Boletim da Oficina Sanitária Pan-Americana 114:415-428.

Pascal G 1996. O pensamento de Kant. (5a ed.). Tradução de Raimundo Vier. Vozes, Petrópolis.

Paugam S 1999. Abordagem sociológica da exclusão, pp. 49-62. In MPB Veras (org.). Por uma sociologia da exclusão social. O debate com Serge Paugam. EDUC, São Paulo.

Platão 1987. A República. Introdução, tradução e notas de Maria Helena da Rocha Pereira. Fundação Calouste Gulbenkian, Lisboa.

Platão 1992. Górgias. Introdução, tradução e notas de Manuel de O. Pulquério. Edições 70, Lisboa.
Rawls J 1992. Justiça como eqüidade: uma concepção política, não metafísica. Lua Nova 25:25-29

Rawls J 1996. Political liberalism. Columbia University Press, Nova York.

Rawls J 1997. Uma teoria da justiça. Tradução de A. Pisetta e L. M. R. Esteves. Martins Fontes, São Paulo.

Rawls J 1999. A kantian conception of equality. Collected Papers. Harvard University Press, Harvard.

Reale G 1999a. História da filosofia antiga: das origens a Sócrates. Tradução Marcelo Perine. (3a ed.). Loyola, São Paulo. Vol. 1.

Reale G 1999b. História da filosofia antiga: léxico, índices e bibliografia. Tradução Marcelo Perine. (3a ed.). Loyola, São Paulo. Vol. 5.

Ribeiro CDM 2003. "Cultura dos limites", justiça sanitária e alocação de recursos: argumentações racionais acerca dos conflitos morais em medicina intensiva neonatal, do ponto de vista dos profissionais intensivistas. Tese de doutorado. Escola Nacional de Saúde Pública, Fiocruz, Rio de Janeiro.

Rocha S 2003. A pobreza no Brasil: afinal, do que se trata? FGV Editora, Rio de Janeiro.

Rousseau JJ 1989. O contrato social. Tradução de Antonio de Padua Danesi. Martins Fontes, São Paulo

Santos SS, Almeida LC, Gomes AP, Engel DC \& SiqueiraBatista R 2001. Leptospirose: Estudo Clínico. Ars Cvrandi 34(5):46-55.

Schramm FM 1998a. A autonomia difícil. Bioética 6(1):27-37.

Schramm FM 1998b. Princípio de justiça: equidade e/ou imparcialidade. Medicina 12(89):8-9.

Schramm FR 2000a. Bioética, economia e saúde. Revista Brasileira de Cancerologia 46(1):41-47.

Schramm FR 2000b. A difícil dialética entre economia e ética. Revista Brasileira de Educação Médica 24(1): 77-81.

Schramm FR 2003. Métodos de la bioética para análisis y solución de los dilemas morales, pp. 59-69. In SD Bergel \& N Minyersky (orgs.). Bioética y derecho. Rubinzal-Culzoni, Buenos Aires.

Schramm FR \& Kottow M 2001. Princípios bioéticos en salud pública: limitaciones y propuestas. Cadernos de Saúde Pública 17(4):949-956.

Schütz G 2002. Quando o "igual tratamento" acaba em injustiça. Um paradoxo bioético das politicas sanitárias universalistas de alocação de recursos. Dissertação de mestrado. Escola Nacional de saúde Pública, Fiocruz, Rio de Janeiro.

Sen A 1980. Equality of what?, pp. 34-48. In S McMurrin (org.). Tanner lectures on human values. Cambridge University Press, Cambridge.

Sen A 1985a. Well-being, agency and freedom. Journal of Philosophy 82(4):169-221. 
Sen A 1985b. Commodities and capabilities. North Holland, Amsterdã.

Sen A 1987. On ethics and economics. Blackwell, Oxford.

Sen A 1990. The standard of living (The Tanner lectures). Cambridge University, Cambridge.

Sen A 1992. Comportamento econômico e sentimentos morais. Lua Nova 25(1):103-130.

Sen A 1996. Capacidad y bienestar, pp 54-83. In M Nussbaum \& A Sen (orgs.). La calidad de vida. Fondo de Cultura Económica, Cidade do México.

Sen A 2001. Desigualdade reexaminada. Tradução e apresentação de Ricardo Doninelli Mendes. Ed. Record, Rio de Janeiro.

Sen A 2002. ¿Por qué la equidade en salud? Pan American Journal of Public Health 11(5-6):302-309.

Silva LMV, Paim JS \& Costa MCN 1999. Desigualdades na mortalidade, espaço e estratos sociais. Revista de Saúde Pública 33(2):187-197.

Siqueira-Batista R 1996. Contexto de formação da sociedade brasileira: impactos sobre a saúde. Arquivos Brasileiros de Medicina 70:531-537.

Siqueira-Batista R 2003. Deuses e homens. Mito, filosofia e medicina na Grécia Antiga. Landy, São Paulo.

Siqueira-Batista R \& Schramm FR 2004. Platão e a medicina. História, Ciências, Saúde - Manguinhos 11(3): 619-634.

Telles V 1994. Pobreza, movimentos sociais e cultura política: notas sobre as (difíceis) relações entre pobreza, direitos e democracia, pp. 225-243. In E Diniz, JSL Lopes \& R Prandi (orgs.). O Brasil no rastro da crise. Hucitec, São Paulo.
Tomás de Aquino 1944-1961. Suma teológica. Faculdade de Filosofia Sedes Sapientiae, São Paulo.

van Stralen C 1996. The struggle over a national health system. The "Movimento Sanitário" and health policymaking in Brazil: 1960-1990. Universiteit Utrecht.

Veras MPB 1999. Notas preliminares sobre exclusão social, um problema brasileiro de 500 anos, pp. 13-46. In MPB Véras (org.). Por uma sociologia da exclusão social. O debate com Serge Paugam. EDUC, São Paulo.

Vergara C 2000. El contexto de las reformas del sector de la salud. Pan American Journal of Public Health 8(12):7-12.

Viana ALA, Fausto MCR \& Lima LD 2003. Política de saúde e eqüidade. São Paulo em Perspectiva 17(1): 58-68.

Victora CG, Barros FC \& Vaughan JP 1989. Epidemiologia da desigualdade. Hucitec, São Paulo.

Vita A 1999a. Uma concepção liberal-igualitária de justiça distributiva. Revista Brasileira de Ciências Sociais 14(39):41-59.

Vita A 1999b. Justiça distributiva: a crítica de Sen a Rawls. Dados - Revista de Ciências Sociais 42(3):471-496.

Wagstaff A 2001. Poverty and health. WHO Commission on Macroeconomics and Health, Boston. Working Group №1, Working paper № 5.

Wagstaff A 2002. Pobreza y desigualdades en el sector de la salud. Pan American Journal of Public Health 11(56):316-326.

Wittgenstein L 1987. Tratado lógico-filosófico e investigações filosóficas. Introdução de Tiago de Oliveira e tradução de M. S. Lourenço. Fundação Calouste Gulbenkian, Lisboa.

Artigo apresentado em 1ㅇ/3/2004

Aprovado em 15/8/2004

Versão final apresentada em 20/8/2004 